\author{
Research Article
}

\title{
Protective effect of aqueous extracts from Canarium odontophyllum Miq. leaf on liver in streptozotocin-induced diabetic rats
}

\author{
Siti Balkis Budin ${ }^{1}$, Shashi Kumar ${ }^{1}$, Nor Malia Abd Warif ${ }^{1}$, Shafikha Mohd Saari ${ }^{1}$, Dayang Fredalina \\ Basri $^{1 *}$ \\ I School of Diagnostic \& Applied Health Sciences, Faculty of Health Sciences, Universiti Kebangsaan Malaysia, Jalan Raja Muda Abdul Aziz, 50300 Kuala \\ Lumpur, Malaysia
}

\begin{abstract}
The fruit of Canarium odontophyllum Miq. is a traditional delicacy in Borneo for its anti-aging benefit. This study evaluated the protective effect of $C$. odontophyllum leaf aqueous extract on damaged liver in streptozotocin-induced diabetic rats. A total of 30 male Spraque-Dawley rats $(150-250 \mathrm{~g})$ were randomly divided into three groups: control group, diabetic without treatment and diabetic treated with $300 \mathrm{mg} / \mathrm{kg}$ aqueous extract of $C$. odontophyllum for 28 consecutive days. The diabetic condition was induced by intraperitoneal injection of streptozotocin at $65 \mathrm{mg} / \mathrm{kg}$ body weight. At the end of study period, blood was collected to assess the biochemical changes and the oxidative stress markers whereas the liver section was examined for morphological changes. Result showed that the level of aspartate transaminase (AST), alanine transaminase (ALT), total bilirubin, gamma-glutamyl transferase (GGT) and alkaline phosphatase (ALP) in diabetic rats treated with $C$. odontophyllum were significantly reduced $(\mathrm{p}<0.05)$ compared to untreated diabetic group. Results showed an improvement in oxidative stress markers as presented by lower level of malondialdehyde (MDA) and protein carbonyl as well as higher level of reduced glutathione (GSH) and superoxide dismutase (SOD) and glutathione peroxidase (GPx) activity in C. odontophyllum treated group compared to untreated diabetic group. Histologically, there were no obvious morphological changes in both diabetic groups. These findings demonstrated that the aqueous extract of $C$. odontophyllum has the potential to reduce oxidative stress in liver of streptozotocin-induced diabetic rat.
\end{abstract}

Keywords: Canarium odontophyllum Miq., antidiabetic, medicinal plant, liver damage, protective effect

Introduction

According to World Health Organization report, diabetes mellitus is a chronic disease caused by failure of pancreas to produce sufficient insulin, or when the body is unable to use the produced insulin effectively (WHO 1999). Under normal circumstances, blood glucose levels are regulated by insulin. Diabetes is widespread throughout the world and the prevalence of diabetes worldwide is expected to be $2.8 \%$ in 2000 and expected to increase to $4.4 \%$ in 2030 (Wild et al. (2004).

In diabetic condition, either the increase of prooxidant or the decrease of antioxidant status may occur, thus leading to oxidative stress (Forbes et al., 2003). The increased of oxidative stress in diabetes is multifactorial, whereby the autoxidation of glucose plays an important role in the formation of reactive oxygen species (ROS). ROS may attack the tissues and organs in the body that will give rise to various clinical abnormalities (Bagri et al. 2009). Antioxidant promotes the elimination of free radicals and disturbances in its activity may further cause oxidative stress (Rahimi et al., 2005). Oxidative stress condition in diabetic patients play a role in pathogenesis of long-term complications, such as neuropathy, nephropathy and microangiopathy which lead to higher risk of morbidity and mortality (Kuyvenhoven \& Meinders 1999; Lipinski 2001; Rains and Jain 2011).

Canarium ondontophyllum Miq. is classified under the Burseraceae family and can be found in the tropical rain forest of Sarawak, Malaysia often being consumed as nutritious ingredient by the local community (Chew et al., 2012). Previous study done on other Canarium species has revealed that the leaves of $C$. schweinfurthii Engl. has high antioxidant activity (Ngbede et al., 2008). According to Chew et al. (2012), phytochemical analysis of the leaves of $C$. patentinervium Miq. showed the presence of tannin and flavonoid which act as antimicrobial and free radical scavenger. Tannin extracted from the leaves, twigs and stem bark of C. album showed 1,1-depheny-2-picrylhydrazyl (DPPH) activity (Zhang \& Lin, 2008). C. subulatum, C. zeylanicum, C. boivinii and C. manii contained the chemical components such as terpenoids, tannins and bioflavonoids (Mogana et al., 2011). Biological studies shown that certain Canarium species have hepatoprotective, antidiabetic (Mokiran et al. 2014) and antioxidant properties (Anand et al., 1992). Azlan et al. (2010) reported that the fruit of C. odontophyllum especially its outer skin contains high level of antioxidant compounds such as phenolic, flavonoid and anthocyanin.

\footnotetext{
* Correspondence: Dayang Fredalina Basri, School of Diagnostic \& Applied Health Sciences, Faculty of Health Sciences, Universiti Kebangsaan Malaysia, Jalan Raja Muda Abdul Aziz, 50300 Kuala Lumpur, Malaysia. Fax: +60326929032.
}

e-Mail: dayang@ukm.edu.my

(C) 2018 by the Author(s). Published by WWH Networks Sdn Bhd. Attribution-ShareAlike 4.0 International (CC BY-SA 4.0). This open access article is distributed based on the terms and conditions of the Creative Commons Attribution license https://creativecommons.org/licenses/by-sa/4.0/ 
To date, no studies have been conducted on the $C$. odontophyllum leaves as an alternative treatment to reduce the complications associated with diabetes mellitus. The objective of this study was to identify the potential of $C$. odontophyllum to be used in the prevention against liver damage in streptozotocin-induced diabetic rat.

\section{0 \\ Material and methods}

2.1

Plant materials

Fresh C. odontophyllum leaves were collected from Kuching, Sarawak, Malaysia. The leaves were deposited in the Herbarium University Kebangsaan Malaysia in Bangi, Malaysia with voucher specimen number UKMB40052.

\subsection{Preparation of aqueous extract from C. odontophyllum leaves}

The $C$. odontophyllum leaves were washed and dried in an oven at $50^{\circ} \mathrm{C}$ until constant weight was obtained. The dried leaves were grounded into fine powder using an electric grinder. About $100 \mathrm{~g}$ of powdered leaves were soaked in $500 \mathrm{ml}$ sterile distilled water at a ratio of 1:5 (w/v) at room temperature and shaken on an orbital shaker at $100 \mathrm{rpm}$ overnight. The mixture was centrifuged at $3000 \mathrm{rpm}$ for $5 \mathrm{~min}$ and the supernatant was collected. The supernatant was then filtered through Whatman No. 1 filter paper and freeze-dried under vacuum at $-50^{\circ} \mathrm{C}$ to produce a fine crystal-like crude aqueous extract. The powdered extract was kept in an air-tight container and stored at $4{ }^{\circ} \mathrm{C}$ until further use.

\section{Experimental animals}

Thirty male Sprague-Dawley rats weighing between 200 to $250 \mathrm{~g}$ obtained from the Animal Unit, Universiti Kebangsaan Malaysia were used for this study. They were kept in polycarbonate cages and allowed to acclimatize for 7 days before experiment started and maintained under laboratory conditions of temperature, humidity and light. Standard rat pellet and tap water were provided ad libitum throughout the study period. The rats were randomly divided into three groups and each group comprised 10 rats: normal (N), diabetic control (STZ group) and $C$. odontophyllum -treated diabetic group (STZ+CO group).

The rats were fasted overnight prior to diabetes induction. Diabetes was induced by injection of a single intraperitoneal at the dose of $65 \mathrm{mg} / \mathrm{kg}$ body weight (Saari et al. 2017). Three days after STZ injection, fasting blood glucose were determined using a glucometer and rats with fasting blood glucose level above $15 \mathrm{mmol} / \mathrm{L}$ were considered for this study (Budin et al., 2013). (At the end of the study period, the diabetic was confirmed again by analyzing blood glucose level using hexokinase assay).

The extract was administered orally by force feeding daily at the dose of $300 \mathrm{mg} / \mathrm{kg}$ for 28 days. The choice of $300 \mathrm{mg} / \mathrm{kg}$ as the dose of the extract was based on Kamtchouing et al. (2006) which reported that the dose (from the stem bark extract of Canarium schweinfurthii Engl) showed anti-diabetic activity. At the end of the experimental period, the rats were fasted overnight, anethesized using chloroform and blood was drawn by cardiac puncture. The liver was immediatelly excised and washed with $0.9 \%$ cold normal saline before kept frozen at $80^{\circ} \mathrm{C}$ until used.

All experiments were performed in accordance with the procedures approved by Universiti Kebangsaan Malaysia Animal Ethics Committee (UKMAEC), (Approval No. FSK/BIOMED/2013/MALIA/13-NOV/554-NOV-2013-AUG-2015).

\section{Preparation of liver homogenate}

Liver sample $(1 \mathrm{~g})$ was homogenized using ultra-Turrax homogenizer in $10 \mathrm{ml}$ of $1.15 \% \mathrm{KCl}$ and centrifuged at $13000 \mathrm{rpm}$ for 15 min at $4^{\circ} \mathrm{C}$ and the same process was repeated twice. The supernatant was then removed and stored in an eppendorf tube and kept at $-40{ }^{\circ} \mathrm{C}$. The supernatant was used for oxidative stress marker evaluation and the whole process was conducted in cold condition.

Biochemical assays

The blood was centrifuged at $4000 \mathrm{rpm}$ for $5 \mathrm{~min}$ at $4^{\circ} \mathrm{C}$ to obtained the serum. Serum liver biomarkers (alanine aminotransferase (ALT), aspartate aminotransferase (AST), alkaline phosphatase (ALP), total bilirubin and gamma glutamyltransferase (GGT)) were measured using automated chemical analyzer (Beckam Coulter AU400).

\section{Measurement of antioxidant activity}

Malondialdehyde (MDA) level was measured with Ledwozyw et al. (1986) method as modified by Gwarzo et al. (2014). Protein carbonyl was measured based on its reaction with 2,4-dinitrophenylhydrazin (DNPH) as demonstrated by Levine et al. (1990). Superoxide dismutase (SOD) activity was determined in liver homogenate according to the method of Beyer and Fridovich (1987). Reduced glutathione (GSH) was measured with the method according to Ellman (1959) as described by Giustarini et al. (2014). Glutathione peroxidase (GPx) activity in liver homogenate was determined according to Flohe \& Gunzler (1984).

\section{Histological examination}

The liver tissues were immediately washed in normal saline and fixed in $10 \%$ formalin solution. The sections were analyzed via haematoxylin and eosin staining (H\&E staining) and examined under a light microscope. Histopathological changes were studied by evaluating the tissue slides.

\section{$2.8 \quad$ Statistical analyis}

The Statistical Packager for the Social Science 21 (SPSS 21), was used for statistical analysis. All variables were checked for normality and homogeneity of variance. The data obtained were tested using one-way ANOVA followed by Tukey's post hoc multiple comparison test. The value of $\mathrm{p}<0.05$ was considered statistically significant. All data were expressed as mean \pm SEM. 


\section{Results}

3.1 Effect of aqueous extract from C. odontophyllum on body weight

As shown in Table 1, the body weight of both STZ group and STZ+CO group showed a significant drop compared to the normal (N) group. The C. odontophyllum extract at $300 \mathrm{mg} / \mathrm{kg}$ did not improve body weight loss in diabetic rat.

3.2 Effect of C. odontophyllum extract on the liver injury biomarkers

The effect of aqueous extract of $C$. odontophyllum on the liver injury biomarkers in diabetic rats are shown in Table 2. The level of ALT, AST, ALP, total bilirubin and GGT in serum of STZ group were found to be significantly increased compared to N group (p<0.05). It was observed that the $C$. odontophyllum extract was capable to reduce all liver injury biomarkers in STZ + CO group.

Table 1 The body weight of all experimental group.

\begin{tabular}{ll}
\hline Group & Body weight $(\mathrm{g})$ \\
\hline $\mathrm{N}$ & $341.08 \pm 25.4$ \\
$\mathrm{STZ}$ & $232.65 \pm 10.51^{\mathrm{a}}$ \\
$\mathrm{STZ}+$ C. odontophyllum & $214.17 \pm 16.7^{\mathrm{a}}$ \\
$300 \mathrm{mg} / \mathrm{kg}$ & \\
\hline
\end{tabular}

Value expressed as mean \pm SEM.

a significant difference compared with $\mathrm{N}$ group
Table 2 The effect Canarium odontophyllum leaves at 300mg/kg on liver injury biomarkers

\begin{tabular}{llll}
\hline & \multicolumn{2}{l}{ Groups } & \\
\cline { 2 - 4 } Parameters & $\mathrm{N}$ & $\mathrm{STZ}$ & $\begin{array}{l}\text { STZ }+ \\
\text { C. odontophyllum } \\
300 \mathrm{mg} / \mathrm{kg}\end{array}$ \\
\hline ALT (U/L) & $61 \pm 1.8$ & $380 \pm 258^{\mathrm{a}}$ & $319 \pm 81$ \\
AST (U/L) & $108 \pm 21$ & $397 \pm 268^{\mathrm{a}}$ & $325 \pm 81$ \\
ALP (U/L) & $204 \pm 47$ & $1559 \pm 502^{\mathrm{a}}$ & $1287 \pm 452$ \\
$\begin{array}{l}\text { TBIL } \\
\text { (mmol/L) }\end{array}$ & $2.35 \pm 0.25$ & $4.11 \pm 1.24^{\mathrm{a}}$ & $3.6 \pm 1.03$ \\
GGT (U/L) & $1.18 \pm 0.15$ & $4.05 \pm 0.65^{\mathrm{a}}$ & $3.15 \pm 1.33$ \\
\hline
\end{tabular}

Value expressed as mean \pm SEM.

${ }^{a}$ significant difference compared with $\mathrm{N}$ group

\subsection{Effect of C. odontophyllum extract on oxidative stress markers}

The level of MDA, protein carbonyl and GSH as well as GPx and SOD activity in the liver homogenate are shown in Table 3. In STZ group, the SOD, GPx and GSH status were significantly reduced, while the protein carbonyl and MDA level were significantly higher when compared with $\mathrm{N}$ group ( $\mathrm{p}<0.05$ ). The aqueous extract of $C$. odontophyllum significantly decreased the protein carbonyl level of the diabetic rat. On the other hand, the extract improved the antioxidant status in STZ+CO group compared to untreated diabetic group. However, the improvement in oxidative stress biomarkers were not significant.

Table 3 The effect of Canarium odontophyllum leaves at $300 \mathrm{mg} / \mathrm{kg}$ on oxidative stress markers of the liver

\begin{tabular}{llll}
\hline & Groups & \\
\cline { 2 - 4 } Parameters & $\mathrm{N}$ & $\mathrm{STZ}$ & $\begin{array}{l}\text { STZ }+ \\
\text { C. odontophyllum } \\
300 \mathrm{mg} / \mathrm{kg}\end{array}$ \\
\hline MDA (nmol/mg protein) & $3.17 \pm 0.571$ & $4.68 \pm 0.90^{\mathrm{a}}$ & $3.96 \pm 0.485$ \\
Protein carbonyl (mg/ml) & $0.066 \pm 0.012$ & $0.173 \pm 0.029^{\mathrm{a}}$ & $0.112 \pm 0.025^{\mathrm{b}}$ \\
GSH (mM/mg protein) & $0.011 \pm 0.011$ & $0.008 \pm 0.002^{\mathrm{a}}$ & $0.009 \pm 0.001$ \\
SOD (U/min/mg protein) & $0.69 \pm 0.05$ & $0.345 \pm 0.18^{\mathrm{a}}$ & $0.415 \pm 0.116$ \\
GPx (nmol/min/mg protein) & $0.025 \pm 0.005$ & $0.019 \pm 0.005^{\mathrm{a}}$ & $0.021 \pm 0.003$ \\
\hline
\end{tabular}

Value expressed as mean \pm SEM.

${ }^{\mathrm{a}}$ significant difference compared with $\mathrm{N}$ group and ${ }^{\mathrm{b}}$ significant difference compared with $\mathrm{STZ}$ group

3.4 Effect of C. odontophyllum extract on morphological changes of liver

Histopathological photographs from Figure 1 showed that there were no obvious morphological changes observed under microscopic observation in both the STZ and STZ + CO group. The hepatocytes were well organized in plates and no necrosis and inflammatory cells were noted. 

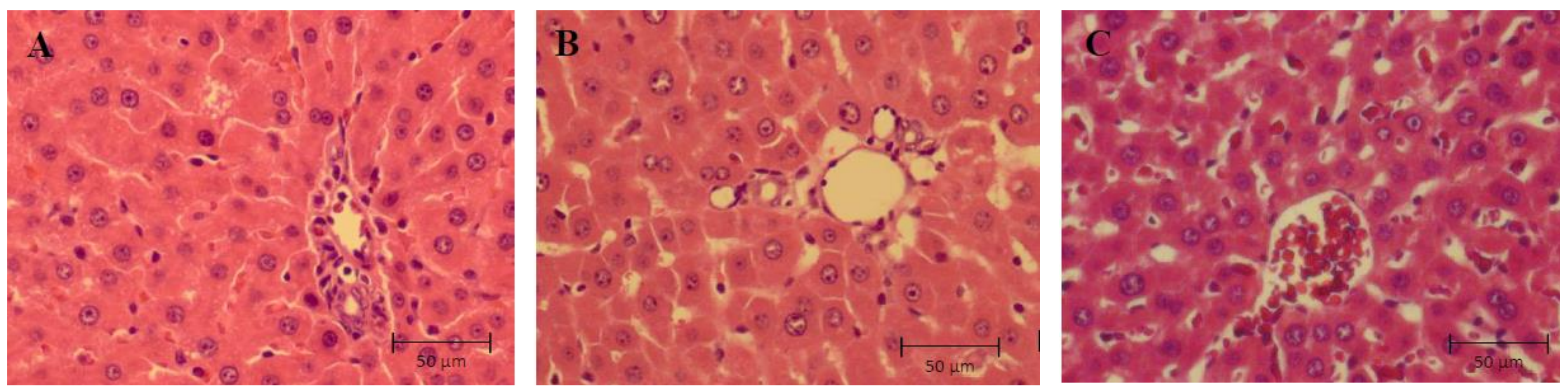

Figure 1 Microscopic photographs of the liver tissue in (A) N group (B) STZ group and (C) STZ + CO.

Note that there were no obvious morphological changes in both diabetic groups (Magnification X40)

\section{0 Discussion}

There was a significant decreased in the body weight of diabetic rats. In insulin deficiency, peripheral cells are unable to use glucose as energy source. Body weight progressively reduced due to energy source being rerouted from glucose metabolism to fat and muscle from the process of lipolysis and proteolysis respectively. The diabetic rats treated with $C$. odontophyllum showed no signs of weight elevation after 28 days of treatment which was in accordance with Mokiran et al., (2014).

This study found that there was an increased in the level of all liver injury biomarkers in STZ group indicate the occurence of liver injury in diabetic rats. These findings are consistent with He et al. (2009) which showed an increased in liver enzyme level in diabetic rats. Diabetes also caused the fat accumulation in the liver and acts as substrates for lipid peroxidation (Gutteridge, 1995) which causes damage to the membrane and initiates liver injury. There was an improvement in liver biomarkers following treatment with C. odontophyllum indicating the potential of extract in minimizing the liver damage in diabetic condition. Previous study showed that the usage of aqueous extract from the leaves of Moringa oleifera which has high antioxidant properties was found to offer protection for liver in diabetic condition (Jaiswal et al. 2013).

Diabetes cause excess in generation and decrease in destruction of ROS which subsequently increase MDA and protein carbonyl level (Yoshikawa and Naito, 2002) and altered the antioxidant status (Aragno et al., 1999). According to Cai et al., (2017) the antioxidant activity will be decreased after the exposure of cell to high glucose level. $C$. The reduction in antioxidant status diabetic rats is in line with Abolfathi et al., (2012) hence, suggesting that the induction of STZ can cause oxidative stress in the liver.

C. odontophyllum treatment was able to reduce MDA and protein carbonyl besides improving antioxidant defense system in diabetic rat. It shows that aqueous $C$. odontophyllum leaf extract has the capacity to reduce oxidative stress in diabetic condition and demonstrate its potential as a protective agent from free radical damage. The increase in antioxidant enzymes in the group treated with $C$. odontophyllum may be due to rich phenolic content in the leaves of $C$. odontophyllum (Chew et al., 2012). Furthermore, Mokiran et al. (2014) also supported that Canarium species has the hepatoprotective and antidiabetic effects. Canarium species has high antioxidant properties and rich with antioxidant compound such as phenolic, flavonoid and anthocyanin (Anand et al., 1992; Azlan et al., 2010). The result of this study corresponded with Prabakaran \& Ashokkumar (2013) which observed an increased antioxidant activity in diabetic rats treated with esculetin which is a coumarin derivative with high antioxidant activity (Witaicenis et al. 2013).

Based on the histological observation of liver tissues in this study, there were no obvious morphological alteration in both diabetic groups which indicated that the increase in liver injury oxidative stress biomarkers did not correlate with the histopathological findings. The liver injury that occurs in the present study was not severe enough to cause significant morphological changes from the histopathological observation.

Histological observation was performed on the liver sections to examine any abnormality in the tissue. In this study, no abnormal cells are seen in all experimental groups. This result was not consistent with Abolfathi et al., (2012) where the group which was exposed to STZ for 32 days can lead to the formation of hepatocytes with various sizes and with the presence of inflammatory cells and fat globule.

\section{0}

\section{Conclusion}

The findings from the present study provide evidence that the leaves from $C$. odontophyllum leaves can be utilized as an alternative treatment to reduce the complications associated with diabetes mellitus specifically in the prevention of liver damage on streptozotocin-induced diabetic rat by providing protection against oxidative stress with significant antioxidant effect.

\section{0 \\ Acknowledgements}

This study was funded by Universiti Kebangsaan Malaysia under the Research University Grant code GUP-2014-059.

\section{0}

\section{References}

Abolfathi AA, Mohajeri D, Rezaie A, Nazeri M. Protective effects of green tea extract against hepatic tissue injury in streptozotocin-induced diabetic rats. Evid-Based Compl Alt. 2012; Volume 2012: Article ID 740671, 10 pages.

Aragno M, Tamagno E, Gatto V, Brignardello E, Parola S, Danni O, Boccuzzi G. Dehydroepiandrosterone protects tissues of streptozotocintreated rats against oxidative stress. Free Radical Bio Med. 1999;26(11):1467-74.

Anand KK, Gupta VN, Rangari V, Singh B, Chandan BK. Structure and hepatoprotective activity of a biflavonoid from Canarium manii. Planta Med. 1992;58(06):493-5.

Arai K, Maguchi S, Fujii S, Ishibashi H, Oikawa K, Taniguchi N. Glycation and inactivation of human Cu-Zn-superoxide dismutase. Identification of the in vitro glycated sites. J Biol Chem. 1987;262(35):16969-72.

Azlan A, Prasad KN, Khoo HE, Abdul-Aziz N, Mohamad A, Ismail A, Amom Z. Comparison of fatty acids, vitamin E and physicochemical properties of Canarium odontophyllum Miq. (dabai), olive and palm oils. J Food Compos Anal. 2010;23(8):772-6. 
Bagri P, Ali M, Aeri V, Bhowmik M, Sultana S. Antidiabetic effect of Punica granatum flowers: effect on hyperlipidemia, pancreatic cells lipid peroxidation and antioxidant enzymes in experimental diabetes. Food Chem Toxicol. 2009;47(1):50-4.

Bailey SA, Zidell RH, Perry RW. Relationships between organ weight and body/brain weight in the rat: what is the best analytical endpoint? Toxicol Pathol. 2004;32(4):448-66.

Beyer WF,Fridovich I. Assaying for superoxide dismutase activity: Some large consequences of minor changes in conditions. Anal Biochem. 1987;161(2): 559-66.

Budin SB, Ismail H, Chong PL. Psidium guajava fruit peel extract reduces oxidative stress of pancreas in streptozotocin-induced diabetic rats. Sains Malays. 2013;42(6):707-13.

Cai L, Lin C, Yang N, Huang Z, Miao S, Chen X, Pan J, Rao P, Liu S. Preparation and characterization of nanoparticles made from coincubation of SOD and Glucose. Nanomaterials 2017; 7:458,11 pages.

Chew LY, Khoo HE, Amin I, Azrina A, Lau CY. Analysis of phenolic compounds of dabai (Canarium odontophyllum Miq.) fruits by highperformance liquid chromatography. Food Anal Method. 2012;5(1):126-37.

Chiou TJ, Zhang J, Ferrans VJ, Tzeng WF. Cardiac and renal toxicity of menadione in rat. Toxicology. 1997;124(3):193-202.

Dalle-Donne I, Rossi R, Giustarini D, Milzani A, Colombo R. Protein carbonyl groups as biomarkers of oxidative stress. Clin Chim Acta. 2003;329(1):23-38.

Ellman GL. Tissue sulfhydryl groups. Arch Biochem Biophys.1959; 82(1): 70-7.

Flohé L, Günzler WA. Assays of glutathione peroxidase. Methods Enzymol. 1984;105:114-21.

Forbes JM, Cooper ME, Oldfield MD, Thomas MC. Role of advanced glycation end products in diabetic nephropathy. J Am Soc Nephrol. 2003;14(3): S254-8.

Giustarini D, Fanti P, Matteucci E, Rossi R. Micro-method for the determination of glutathione in human blood. J Chromatogr B Analyt Technol Biomed Life Sci. 2014; 964:191-4.

Gutteridge JM. Lipid peroxidation and antioxidants as biomarkers of tissue damage. Clin Chem. 1995;41(12):1819-28.

Gwarzo MY, Ahmadu JH, Ahmad MB, Dikko AUA. Serum glucose and malondialdehyde levels in alloxan induced diabetic rats supplemented with methanolic extract of Tacazzea Apiculata. Int J Biomed Sci. 2014;10(4): 236-42.

He Y, Martinez-Fleites C, Bubb A, Gloster TM, Davies GJ. Structural insight into the mechanism of streptozotocin inhibition of O-GlcNAcase. Carbohyd Res. 2009;344(5):627-31.

Jaiswal D, Rai PK, Mehta S, Chatterji S, Shukla S, Rai DK, Sharma G, Sharma B, Khair S, Watal G. Role of Moringa oleifera in regulation of diabetes-induced oxidative stress. Asian Pac J Trop Dis.2013; 426-432.

Kamtchouing P, Kahpui SM, Dzeufiet PD, Tédong L, Asongalem EA, Dimo T. Anti-diabetic activity of methanol/methylene chloride stem bark extracts of Terminalia superba and Canarium schweinfurthii on streptozotocin-induced diabetic rats. J Ethnopharmacol. 2006; 104(3):306-9.

Kuyvenhoven JP, Meinders AE. Oxidative stress and diabetes mellitus: pathogenesis of long-term complications. Eur J Intern Med. 1999;10(1):9-19.

Ledwozyw A, Michalak J, Stepień A, Kadziołka A.The relationship between plasma triglycerides, cholesterol, total lipids and lipid peroxidation products during human atherosclerosis. Clin Chim Acta. 1986; 155(3):275-83.

Levine RL, Garland D, Oliver CN, Amici A, Climent I, Lenz AG, Ahn BW, Shaltiel S, Stadtman ER. Determination of carbonyl content in oxidatively modified proteins. Methods Enzymol. 1990;186:464-78.

Lipinski B. Pathophysiology of oxidative stress in diabetes mellitus. J Diabetes Complicat. 2001;15(4):203-10.

Mogana R, Teng-Jin K, Wiart C. In vitro antimicrobial, antioxidant activities and phytochemical analysis of Canarium patentinervium Miq. from Malaysia. Biotechnol Res Intern. 2011; Volume 2011: Article ID 768673, 5 pages.

Mokiran NN, Ismail A, Azlan A, Hamid M, Hassan FA. Effect of dabai (Canarium odontophyllum) fruit extract on biochemical parameters of induced obese-diabetic rats. J Funct Food. 2014; 8:139-49.

Ngbede J, Yakubu RA, Nyam DA. Phytochemical screening for active compounds in Canarium schweinfurthii (Atile) leaves from Jos North, Plateau State Nigeria. Res J Biol Sci 2008;3(9):1076-8.

Prabakaran D, Ashokkumar N. Protective effect of esculetin on hyperglycemia-mediated oxidative damage in the hepatic and renal tissues of experimental diabetic rats. Biochimie. 2013;95(2):366-73.

Rahimi R, Nikfar S, Larijani B, Abdollahi M. A review on the role of antioxidants in the management of diabetes and its complications. Biomed Pharmacother. 2005;59(7):365-73.

Rahman I, MacNee W. Lung glutathione and oxidative stress: implications in cigarette smoke-induced airway disease. Am J Physiol-Lung C. 1999;277(6): L1067-88.

Rains JL, Jain SK. Oxidative stress, insulin signaling, and diabetes. Free Radical Biol Med. 2011;50(5):567-75.

Rasekh HR, Nazari P, Kamli-Nejad M, Hosseinzadeh L. Acute and subchronic oral toxicity of Galega officinalis in rats. J Ethnopharmacol. 2008;116(1):21-6.

Ravi K, Ramachandran B, Subramanian S. Effect of Eugenia jambolana seed kernel on antioxidant defense system in streptozotocin-induced diabetes in rats. Life Sci. 2004;75(22):2717-31.

Saari SM, Basri DF, Budin SB, AbdWarif NM. Effects of Canarium odontophyllum leaves on plasma glucose and T lymphocyte population in streptozotocin-induced diabetic rats. Saudi J Biol Sci. 2017: 24(2):320-3.

Yoshikawa T, Naito Y. What is oxidative stress? Jpn Med Assoc J. 2002;45(7):271-6.

WHO. Definition, diagnosis and classification of diabetes mellitus and its complications: report of a WHO consultation. Geneva: World Health Organization. 1999.

Wild S, Roglic G, Green A, Sicree R, King H. Global prevalence of diabetes estimates for the year 2000 and projections for 2030 . Diabetes Care. 2004;27(5):1047-53.

Witaicenisi A, Luchinp AC, Hiruma-Lima CA, Felisbino SL, Justulin Jr LA, Garrido-Mesa N, Utrilla P, Galvez J, Di Stasi lC. Mechanism and effect of esculetin in an experimental animal model of inflammatory bowel disease. Eur J Inflamm. 2013; 11(2):433-46

Zhang LL, Lin YM. Tannins from Canarium album with potent antioxidant activity. J Zhejiang Univ-Sc B. 2008;9(5):407-15. 